\title{
Access Barriers and Health Care in Patients with Chronic Respiratory Diseases
}

\author{
Marcio Costa de Souza*, Juliana Costa dos Santos Borges, Kamila Freitas Trindade, Rafaela \\ Silva Santos, Vitória Cézar Santos Gonçalves Brito, Jairrose Nascimento Souza, Caroline Raíza \\ Dourado Lima, Milene Pereira, Joana Paroli Mangabeira Campos, Rocio Andrea Cornejo Quin- \\ tana, Marcia Cristina Graça Marinho, Magno Conceição das Merces, Fernanda Warken Rosa \\ Camelier and Aquiles Assunção Camelier
}

State University of Bahia, Brazil

*Corresponding author: Marcio Costa de Souza, State University of Bahia, Street Silveira martins, 2555: Salvador, Bahia, Brazil.

To Cite This Article: Marcio Costa de Souza, Juliana Costa dos Santos Borges, Kamila Freitas Trindade etx all.., Access Barriers and Health Care in Patients with Chronic Respiratory Diseases. 2020 - 11(1). AJBSR.MS.ID.001594. DOI: 10.34297/AJBSR.2020.11.001594.

Received: 眥 October 08, 2020; Published: 㭗 December 02, 2020

\begin{abstract}
Aim: understand access to health care production in a health district in the city of Salvador-Bahia.

Methods: It is a research of qualitative and exploratory approach, used as a tool for data production the semi-structured interview carried out in 4 Family Health Units (FHU) in the sanitary district, researching 15 people, including health professionals, patients and family members.

Results: After the analysis and ordering of the testimonies, dimensions of access to health were constructed as the main category, which presented barriers of access to geographic, economic and functional. Another evident fact is the presence of health inequities as a structuring element in the society studied and determinant as an obstacle to the knowledge of comprehensive health for patients with these diseases.
\end{abstract}

Conclusion: There is a need to overcome the barriers encountered, and it is only possible by guaranteeing universal, comprehensive and equal access to health as pillars in the implementation of comprehensive and humanized health care.

Keywords: Patient-Centered Care, Outcome Assessment, Health Care, Respiratory Tract Diseases.

\section{Introduction}

Undetected The epidemiological transition has been a real fact in today's society, with technological advances and greater access to health services, mainly due to changes in lifestyle and human behavior [1]. Therefore, chronic diseases have a great influence on the environment and, consequently, on the quality of life of the affected people, which reinforces the need for tools capable of qualifying health promotion actions [2]. However, the health activities of monitoring and controlling these diseases are essential to enable better living conditions for the population with an expanded care network and articulated with Primary Health Care [2,3].

Regarding Chronic Respiratory Diseases(CRD), these have a prominent place due to the great disabling power, as in the case of Asthma and Rhinitis, and in some cases of high mortality, as in Chronic Obstructive Pulmonary Disease(COPD), and still, smoking stands out for its harmful and own power and associated with other health conditions. Therefore, it is necessary that the care provided is centered on the patient, in an interprofessional way and with a production of powerful bonds between the professional and the patient. It is important to note that smoking cessation must be a continuous and relevant action by health authorities [4-6].

For comprehensive care to be offered, é it is necessary that the health actions provided have a different look at chronic diseases, because living with a disease requires an understanding of the whole process, especially the of falling ill, thus, recognizing the sub- 
jectivity of care is essential for health actions to be resolvable and meet the health needs of those affected with CRD [7-9].

So that there is effective care and meets the health needs of patients, ter acesso aos serviços de saúde é primordial, in which the health service user needs to overcome the social inequities represented in the barriers of geographical and economic access, that hinder the practice of universality. Besides that, barriers of a functional nature, that are characterized by the obstacles that exist in health services that care is effective and resolving, which also highlights communication as another tool that can be limited, something that prevents the resolution of comprehensive care.

Considering that access is the enabling step not only for an early diagnosis, but also for effective therapy and a positive prognosis, this study aims to understand access to health care production in a health district in the city of Salvador-Bahia.

\section{Materials and Methods}

It is a research with a qualitative exploratory approach, carried out in four Family Health Units (FHU) in the Cabula/Beirú District chosen intentionally. There is no reference to the "health professionals" group, if defined as the same group consisting of anyone who is in that environment, regardless of their academic training. (physician, nurses, attendants, and other service workers).

As an inclusion criterion, health workers were defined as those who work directly with people with CRD at the FHU and as for users, people who suffer or care for the studied diseases. Regarding the exclusion criterion: they are under eighteen and do not wish to participate in the study. The process of qualitative research does not admit isolated views, it develops in dynamic interaction, constantly feedback and reformulating.

In this way, some tools will be used to give visibility to the studied local events, using, therefore, the meeting as a potentializer in the production of data, in the event. Therefore, the people interviewed were chosen among the workers of the FHU, users and family members in the units studied, which is carried out in the light of a semi-structured script. This tool aims to apprehend the point of view of the subjects, in which it facilitates the opening, broadening and deepening of communication, which leaves the researcher and the study participant, free to discuss the proposed theme. During the interviews, a recorder (Motorola XT 311) was used as a way to guarantee the reliability of the testimonies, however it will only be used with the participant's proper authorization.

In order to systematize the information collected for analysis, the following steps were performed: initially the information was ordered mapping all the data obtained (transcription of recordings, rereading of material, organization of recordings). Then, the information was classified, based on the identification of the core of meanings and, therefore, empirical categories called "dimensions of access to health" were elaborated according to Souza [13].

Finally, for the moment of final analysis of the information, there was an articulation of the empirical data with the theoretical frameworks of the research and documents, articulating the relationship between the concrete and the abstract, the general and the particular, theory and practice (Minayo). The research was approved by the Ethics Committee of the State University of Bahia under the number 61478016.0.0000.0057.

\section{Results and Discussion}

In summary, fifteen people participated in the research, among which we have: service users, their families and health professionals. The number of respondents was considered satisfactory due to the recurrence of information, since in a qualitative research there is no concern with the quantitative to be researched, but with the deepening and comprehensiveness of the phenomenon to be studied. Minayo. The research in its entirety started from the mapping of the process of access to health services, showing positive actions and imposed difficulties.

In this perspective, with the development of data and research production and based on a theoretical framework, it was established as the main category Dimensions of access to health, the data was gathered in four meanings: geographic, economic and functional access.

\section{Dimensions of Access to Health}

When thinking about comprehensive care, it is important to establish an important link in an unequal country with equity and the need to enable universal access to the Health System. To this end, it is of fundamental importance that new arrangements are produced at different points in the network, especially with regard to a complex and heterogeneous system, which despite constant growth, still lives under the aegis of sub-financing [11-15].

Thereby, geographic access, in a country with continental dimensions, must be a crucial element for health planning, it is a challenge to contribute to a resolutive and integral care, which triggers the articulation of care networks, already that this distance can be an element that makes it difficult to continue treatment, especially for those with chronic diseases [16].

In this sense, we understand that the form of use by the user is the factor that facilitates or difficulties in accessing the health service, constituting barriers to access that can interrupt the health care of patients who need it [4]. This statement became noticeable in the following interview,

[...] If you feel sick do you stay at home? Stay at home. I take the nebulizer, take the pill and get better. Because? Because there is no transport for us to go, I am from a village and the Hospital is in another city (Interviewee 7). 
In this case, it is essential to reflect on the modes or methods of territorial planning of these services at different scales and in relation to different health sectors [16]. Concomitantly, it is important to highlight that the geographical factor is fundamental in the origin of inequality, and is directly interconnected with the social determinants that produce inequality, among them, the ability to displace, that is, distance contributes to the worsening of the situation, especially with regard to certain contexts such as rural areas and/or peripheral regions of large cities [17].

[...] It is a patient, in fact, who came from the countryside. He lived in the countryside and came here to his daughter's house for treatment. It is a sad story, he is depressed, with important COPD, with an inguinal hernia needing to have the surgery and the woman to return to the interior, to their place and is unable to return, she has to stay right here (Interviewee 3 ).

Therefore, after these explanations, it is possible to affirm that the issue of the right to health is directly linked to the territory and the way the services are arranged territorially [16]. Concomitantly, it is essential to plan access to health within the geographical limits of each social territory, integrating services, methods and practices through reference and counter-reference in the network HUS [18].

It is worth mentioning that, in view of the existing social inequalities rooted in Brazilian society, which increases the barrier of economic access and, consequently, an abyss is permeated in relation to this social right established in the Constitution (FIORETEI, 2016). This reality is evident in the following statements,

[...] there is no facility not my daughter. There is no facility! So much so that now his medicine is expensive (Interviewee 4).

[...] I follow up at the hospital because of the medication. The State of Bahia only releases if you are from HUS. And the firecrackers are very expensive ... I feel like staying here at the State University of Bahia and going to the Hospital once a month. For the sake of proximity. The bus to my neighborhood passes at the door, and it is the same to return. So I'm not walking (Interviewee 13).

From this perspective, in the study of economic access to health services, one of the first aspects to consider besides the cost of these services is the user's own displacement, which is proportional to the distance from their home and the way they move [19]. The following statement also contemplates this perspective addressed,

[...] It is always the neighbor who has an Uber business and we ask her to take him. She gives the number, we call the boy and he comes. The last time it was a ride that I paid the driver, but it is always a difficulty (Interviewee 4).

However, it should be noted that policies to reduce social inequalities, both in access and in the use of health services, despite being strongly influenced by the territory factor, will not be able to modify social inequalities in this context if they are not accompanied by comprehensive policies aimed at equity and, at the same time, of actions that seek to change micropolitical health care for an improvement in quality [20].

It is noticeable that the economic factor, when in deficit, represents important impacts not only on the quality of the service provided, but also on access to it, which results in the wasting of health care. In this way, restrictions on access to health, based on economic barriers, constitute an irreparable setback, even violating the Federal Constitution itself. This diversity of approach reflects the importance of access in the promotion and implementation of public policies and its potential for upward changes in the organization of HUS [18].

The experience of individuals accessing direct or indirect contact with health services says a lot about the system's ability to match their expectations and needs [20]. Through this explanation, we contribute to another characteristic of access to health: the functional. In concept, this characteristic involves the entry itself to the services that the citizen at that moment needs [13]. That is, it is understood as the relationship between the way the offer is organized to accept the user [18]. From this perspective, through the testimonies collected, the difficulty that still exists in the practice of the service, to meet the demands of users, becomes explicit,

[...] I started treatment at the hospital, but the doctor made me a nobody. When she was really close to seeing me, she sent for the doctor to be booked, they booked for three months, nine days left for three months I couldn't take it anymore, my son came from São Paulo quickly and took me to São Paulo, there I was admitted and I had my treatment (Interviewee 14).

It is noticed, therefore, that the functional access is related to the types of services offered, the scheduled times and the quality of the service provided, meeting the real demand and constituting a system that ensures comprehensive care [13]. Congruent to this, a human and social right, in this specific case: the right to health must reflect, within the scope of public policies. respect for the multiple singularities that make up the complex demand of the population using health services [21].

It is important to value subjective care, which centralizes actions in care technologies based on qualified listening, singularity and humanization, which qualifies the health service and conditions it to meet the health demands/needs [22].(SILVA et al, 2018) The following statement contemplates how the functional barrier impacts the security of the human right to health,

[...] Yes, but they didn't send me here, they just released me, I went home and I didn't get better (Interviewee 5).

[...] Several times I've had it like this. They said that I would not 
be attended to, that it was not an emergency, and dispensed. Then he said: "everything is fine, this is for major emergencies" (Interviewee 10).

It is important to highlight that the evaluation of the functional access of a given health service can serve as an instrument of analysis on the quality of care being offered. This analysis can both show practices with satisfactory results, as well as those that need to be rethought within the service's organizational structure, thus aiming at its improvement.

It is important to emphasize that health professionals in services need to have a look at health needs, that is, internalize practices that are patient-centered, with the aim of guiding subjective and humanized and comprehensive care. Therefore, their training, from the University to the processes of permanent education in the daily practice of their practices, must be based on the construction of powerful meetings between the worker and the patient, in the production of networks that stimulate life and living [23].

In addition to these dimensions (geographical, economic and functional), there is another that is unveiled in the study, communicational access, which understands the need to produce dialogues in and between health services. But, the same is built in the initial meeting between the patient in need of care and health workers.

In this sense, the unsatisfactory use of information by the subjects involved in the production of care and, therefore, in health communication, can certainly hinder the provision of humanized, universal and comprehensive care. Portanto, é de fundamental importância que possibilite uma gestão democrática e participativa nos serviços de saúde, que tenha como estratégias ações em saúde que compreendam as singularidades do outro, e assim favoreçam o protagonismo, consequentemente a autonomia dos sujeitos no sentido em que produz saúde [24].

\section{Conclusion}

Concomitant with what was discussed and evidenced throughout the research, it is undeniable to say that having access to health services means ensuring the user's possibility to take care of the health problem that afflicts them. However, the health system needs to be able to meet health demands and needs. It can be observed that the social determinants are fundamental for the understanding of this reality, which is demonstrated through the inequities as they contribute to the production of barriers in the access of patients with chronic diseases, and, in this work, with the respiratory nature.

From this perspective, access to the services offered to people with CKD, despite the actions and health services that are daily offered to its users, there is still a path to be taken and improved for comprehensive care. Thus, understanding that making health access viable considering its dimensions (geographic, economic and functional) can contribute to guaranteeing health in its role as a fundamental social right.

In order for this population, regardless of the disease studied, to be able to receive effective, comprehensive and humanized care, it is necessary that current public policies or that are in planning allow universal, comprehensive and equal access throughout their health care process. Disease.

\section{Conflict of Interest}

There are no conflicts of interest.

\section{References}

1. Tavares J, Lovate T, Andrade I (2018) Epidemiological transition and external causes of mortality in southeastern Brazil. GOT, Journal of Geography and Spatial Planning.

2. Becker RM, Heidemann ITSB (2020) Health promotion in care for people with chronic non-transmitable disease: integrative review. Texto context-enferm 29.

3. Silva LS, Cotta RMM. Rosa COB (2013) Health promotion strategies and primary prevention for coping with chronic diseases: systematic review. PAJPH 34(5): 343-350.

4. Souza MC, Souza JN, Camelier FRW, Camelier AA (2017) Care Production and the Care Network for People with Chronic Respiratory Disease: A Review Study. Physiotherapy Research Magazine 7(4): 1-2.

5. Holmen H, Larsen MH, Sallinen MH, Thoresen L, Ahlsen B, et al. (2020) Working with patients suffering from chronic diseases can be a balancing act for healthcare professionals - a meta-synthesis of qualitative studies. BMC Health Serv Res.

6. Alqahtani JS, Oyelade T, Aldhahir AM, Alghamdi SM, Almehmadi M, et al. (2020) Prevalence, Severity and Mortality associated with COPD and Smoking in patients with COVID-19: A Rapid Systematic Review and Meta-Analysis. PLoS ONE 15(5).

7. Franco TB, Hubner LCM (2020) Clinic, care and subjectivity: after all, what kind of care are we talking about? Debate Health 43(6): 93-103.

8. Merhy EE, Feuerwerker LCM, Santos MLM, Bertussi DC, Baduy RS (2019) Basic Network, force field and micropolitics: implications for health management and care. Debate Health 43(6): 70-83.

9. Slomp H, Merhy EE, Seixas CT, Da Cruz KT, Bertussi DC, et al. (2019) Magic or magic? Collegiate managers in the Unified Health System and changes in care modes. Interface - Communication, Health, Education 23.

10. Guimarães WSG, Parente RCP, Guimarães TLF, Garnel L (2018) Access to prenatal care and quality of care in the Family Health Strategy: infrastructure, care, and management. Cad public Health 34(5).

11. Tesser CD, Norman AH, Vidal TB (2018) Access to care in Primary Health Care in Brazil: situation, problems and overcoming strategies. Debate Health 42(1): 361-378.

12. Menezes ELC, Scherer MDA, Verdi MI, Pires DP (2017) Ways of producing care and the universality of access in primary health care. Health and Society 26(4): 888-903.

13. Souza MC. Modelo de atenção no centro de saúde parque floresta Alagoinhas BA: do imaginário a realidade. 2006. 118 f. Dissertação (Mestrado) - Curso de Fisioterapia, Departamento de Saúde, Universidade Estadual de Feira de Santana, Feira de Santana, 2006.

14. Minayo MCS. O desafio do conhecimento: pesquisa qualitativa em saúde. 14 Edição, Editora Hucitec: Sâo paulo, 2014. 
15. Freire MP, Louvison M, Feuerwerker LCM, Chioro A, Bertussi D (2020) Regulation of care in care networks: importance of new technological arrangements. Health and Society 29(3).

16. Battesini M, Coelho HS, Seta MHD (2018) Use of linear programming to optimize geographic access in thematic health care networks. Public Health Notebooks 34(7).

17. Garnelo L, Lima JG, Rocha ESC, Herkrath FJ (2018) Access and coverage of Primary Health Care for rural and urban populations in northern Brazil. Debate Health 42(1): 81-99.

18. Assis MMA, Jesus WLA (2012) Access to health services: approaches, concepts, policies and model of analysis. Science \& Collective Health 17(11): 2865-2875.

19. Fiorati RC, Arcêncio RA, Souza LB (2016) Social inequities and access to health: challenges for society, challenges for nursing. Revista LatinoAmericana de Enfermagem 24.
20. Sales CP, Cavalcante CC, Carvalho DC, Rezende DSB, Bardanachvili E, et al. (2017) Equity in the territory: the dimensions of access to health. Rio de Janeiro: Editora ICICT / FIOCRUZ.

21. Silva CR, Carvalho BG, Cordoni JL, Nunes EFPA (2017) Difficulty in accessing services of medium complexity in small municipalities: a case study. Science \& Collective Health 22(4): 1109-1120.

22. Silva MEA, Reichert APSR, Souza SAF, Pimenta EAG, Collet N (2018) Chronic Disease in Childhood and Adolescence: Links of The Family in the Health Care Network. Text \& Context-Nursing 27(2).

23. Jorge A, Merhy E, Feuerwerker LCM, Bertussi DC, Baduy RS, et al. (2016) Shared Evaluation of Health Care in the Networks. Hexis.

24. Lauer PC (2018) Support in SUS as a strategy for changing the management and care model. Psychology Journal of Unesp 17(2). 